\title{
Early signs of Fournier gangrene: Radiological characteristics
}

\author{
Lin MP1,2,3**, Chen $\mathrm{YL}^{2 * *}$, Cheng JT ${ }^{1}$ and $\mathrm{Lu} \mathrm{CL}^{1}$ \\ ${ }^{1}$ Department of Radiology, Chi-Mei Foundation Medical Center, Chung Hwa Road, Yung Kang City, Tainan, Taiwan, ROC \\ ${ }^{2}$ Department of Medical Technology, Chen Shiu University, Kaohsiung City, Taiwan, ROC \\ ${ }^{3}$ Department of Medical Technology, Chung Hwa University of Medical Technology, Tainan City, Taiwan, ROC \\ \#Both the authors have equal contribution
}

\begin{abstract}
Objective: The goal of this study is to characterize imaging features useful in detecting the early signs of Fournier gangrene (FG). Twenty-seven men and six women, with ages ranging from 31 to 95 years (mean: 61.9) are evaluated. These patients are all documented cases of FG confirmed by blood cultures or pathological specimens.

Method: The CT scans of 29 cases, ultrasound scans of 6 cases, and conventional radiography in 6 cases are reviewed in this study. In conclusion, computed tomography (CT) is the most useful modality in identifying early signs of infection such as fat infiltration ( $\mathrm{p}=0.001)$ and locating the site of infection in the perineum ( $\mathrm{p}=0.014$ ).

Result: Positive findings for the diagnosis of FG are fat stranding ( $\mathrm{n}=28 ; 84 \%$ ), gas formation ( $\mathrm{n}=27$; 81.8\%), abscess formation ( $\mathrm{n}=19$ : 57.5\%), and localized fluid accumulation $(\mathrm{n}=22 ; 66.6 \%)$.

Disease foci in the patients included in our study were located in the perineum $(n=27 ; 81.8 \%)$, scrotum ( $\mathrm{n}=17 ; 51.5 \%)$, perianal region ( $\mathrm{n}=13 ; 39.3 \%)$, the buttocks $(\mathrm{n}=16: 48.4 \%)$, the pubic region ( $\mathrm{n}=9: 27.2 \%)$, and the inguinal region $(\mathrm{n}=9: 27.2 \%)$.

The pathogens isolated in these patients were aerobic in 33 subjects (100\%) and anaerobic in 10 subjects (30.3\%). Mixed florae of 3 different bacteria were observed in 17 subjects (51.5\%), of 4 different bacteria in 9 subjects (27.2\%), of 5 different bacteria in 4 subjects (12.1\%), of 6 different bacteria in 2 subjects (2.6\%), and 8 different bacteria in 1 subject $(1.3 \%)$.
\end{abstract}

Conclusion: Computed tomography (CT) is a helpful imaging modality in establishing early diagnosis of FG by identifying signs of infection such as fat infiltration and disease location in the perineum. Accurate assessment of the extent of disease is also possible and important in prompt and effective planning of treatment.

\section{Introduction}

Fournier gangrene (FG) is a rapidly progressive, necrotizing fasciitis involving the perineal, perianal, or genital regions resulting from polymicrobial infections. This condition is a urologic emergency with a potentially high mortality rate ranging from $15 \%$ to $50 \%[1-$ 5]. Inflammation, edema, and necrosis of the subcutaneous tissues result in compromise of circulation. The interruption in blood supply subsequently causes peri-fascial dissection, allowing for the spreading of bacterial infection throughout the overlying tissues. Due to its rapidly progressive and potentially lethal clinical course, early diagnosis and intervention are crucial [6,7].

Early diagnosis of FG is important because immediate surgical debridement and aggressive antibiotic treatment are indicated. Although FG is often diagnosed clinically, imaging studies play an important role in the early demonstration and accurate assessment of the extent of disease involvement. Whilst conventional radiographs and ultrasonography may provide helpful clues suggesting FG, computed tomography (CT) provides the greatest degree of specificity for both the definitive diagnosis and demonstrating the extent of disease involvement $[1,5,8]$.

To the best of our knowledge, this study is the first to report fat infiltration observed in FG and disease location in the perineum documented by CT. The purpose of this study is to determine whether it is possible to arrive at an early diagnosis based on the afore mentioned features as well as to evaluate the extent of disease involvement by means of CT.

\section{Material and method}

Following the approval of our institution's review board (10002006), we retrospectively reviewed the records of 33 patients with either surgical or microbiologic proof of FG between May of 2005 and October 2010. Our study includes 27 men and 6 women between the ages of 34 and 88 (mean=61.2 years). The diagnosis of FG was established based on blood culture or pathological results along with clinical evidence of infection, including leukocytosis and hyperglycemia $[8,9,10]$. The most common presenting symptoms include perineal swelling, pain, hyperemia, pruritus, gangrene, crepitus and fever [11,12]. The most commonly occurring predisposing factors for the development of FG

${ }^{\star}$ Correspondence to: Lin MP, Department of Radiology, Chi-Mei Foundation Medical Center, Chung Hwa Road, Yung Kang Area, Tainan City, Taiwan, ROC, Tel: +886-6-281-2811 ext. 53139; Fax: +886-6-282-8142; E-mail: linmikea@yahoo.com.tw

Key words: computed tomography, fournier gangrene, radiography, ultrasound Received: June 07, 2018 Accepted: June 18, 2018; Published: June 21, 2018 
is diabetes mellitus in the 33 subjects included in our study. These findings are highly consistent with available published literature, which states that co-morbid conditions, particularly diabetes mellitus, have been found in up to $85 \%$ of patients with FG $[13,14]$.

The documented clinical characteristics, including symptoms, causative organisms, laboratory results, and surgical findings are recorded. The imaging studies of these patients were reviewed (29 CT scans, 6 sonograms, 6 conventional radiographs). Fourteen CT scans were performed with one equipment (X vision TSX002A, Toshiba Corporation, Tokyo, Japan), and 15 scans were performed with another equipment (Light Speed Plus, GE Medical Systems, Milwaukee, WI, USA). In all 29 patients who had undergone CT scans, images were obtained both before and after administration of intravenous contrast material. Scans were performed with a section thickness of $6 \mathrm{~mm}$ to $10 \mathrm{~mm}$. Six patients also underwent ultrasound scans with the GE Logiq 500 Pro Series (GE Medical Systems, Milwaukee, WI, USA), and six patients received conventional radiographic examinations $(\mathrm{KXO}-50 \mathrm{R}$, Toshiba Corporation, Tokyo, Japan).

The obtained CT scans are evaluated for the demonstration of fat stranding, gas formation surrounding the involved structures, and abscess formation or fluid collections. In addition, disease locations are also noted, including the perineum, scrotum, perianal region, buttocks, pubic region and inguinal regions. During the early stages of FG, CT accurately demonstrates fat stranding and infiltration even before the appearance of subcutaneous emphysema. Because of the rapid progression of infection, early signs of FG are defined as stranding in the surrounding fat on initial scans. Microbiological findings of FG are closely correlated with the presence of abscesses, gas formations, and fluid collections observed on CT scans. Based on available published literature, FG is generally located in the perineum $[1,5,8,13,15]$.

\section{Result}

\section{Clinical characteristics}

The clinical symptoms observed in the cases of our study include scrotal swelling in 17 patients, pain in 30 , hyperemia in 29 , pruritus in 23 , crepitus in 20 , and fever in $33[5,11,12]$. The most commonly encountered causative aerobic organisms are Escherichia coli $(\mathrm{n}=23)$, Enterococcus $(\mathrm{n}=15)$, Staphylococcus $(\mathrm{n}=14)$, and Klebsiella $(\mathrm{n}=11)$. Amongst the anaerobic organisms are Bacteroides $(\mathrm{n}=6)$, mixed florae of 3 different organisms $(n=17)$, mixed florae of 4 different organisms $(n=9)$, mixed florae of 5 different organisms $(n=4)$, mixed florae of 6 different organisms $(\mathrm{n}=2)$, and mixed florae of 8 different organisms $(\mathrm{n}=1)$. The white blood cell counts in our cases range from $2.5 \times 10^{9} / \mathrm{L}$ to $36.6 \times 10^{9} / \mathrm{L}\left(\right.$ mean $\left.=17.6 \times 10^{9} / \mathrm{L}\right)$ and were elevated $\left(>9.2 \times 10^{\%} / \mathrm{L}\right)$ in 29 of the 33 patients. C-reactive protein levels in our cases range from $10.3 \mathrm{mg} / \mathrm{dl}$ to $332 \mathrm{mg} / \mathrm{dl}$ (mean=153.7 mg/dl) and were elevated $(>6 \mathrm{mg} /$ $\mathrm{dl}$ ) in 27 of the 33 patients. Blood glucose levels in our cases range from $113 \mathrm{mg} / \mathrm{dl}$ to $691 \mathrm{mg} / \mathrm{dl}(\mathrm{mean}=219.4 \mathrm{mg} / \mathrm{dl})$ and were elevated $(>100$ $\mathrm{mg} / \mathrm{dl}$ ) in all 33 patients. Urine white blood cell counts in our cases range from 0 per HPF to 100 per HPF (mean=27.2 per HPF) and were elevated ( $>0-5$ per HPF) in 12 out of 33 patients.

\section{Computed tomography}

The early signs of FG, including fat infiltration ( $\mathrm{p}=0.001)$ location in the perineum $(p=0.014)$, were observed on CT in our patients. Table 1 details findings observed in patients who had undergone CT scans compared with patients who had not received CT examinations. Tables 1 and 2 compare our findings with those reported in published literature $[5,6]$. Imaging features include fat stranding in 28 patients
(84.8\%) (Figures 1 and 4), abscesses in 19 patients (57.5\%) (Figures 2, 3 and 4), gas formation in 27 patients (81.8\%) (Figures 1, 2 and 4), and localized fluid accumulation in 22 patients (66.6\%) (Figures 2 and 4 ). The location of disease involvement were observed in the perineum in 27 patients $(81.8 \%)$ (Tables 2 and Figures 1 and 4 ), the scrotum in 17 patients (51.5\%) (Figure 2), the peri-anal region in 13 patients (39.3\%), the buttocks in 16 patients $(48.4 \%)$, the pubic region in 9 patients (27.2\%), and the inguinal regions in 9 patients $(27.2 \%)$. CT was also able to detect early stages of FG in the absence of subcutaneous emphysema $[5,16]$.

\section{Ultrasonography}

Ultrasonographic findings of the 6 patients who underwent this imaging study all exhibited hyperechoic foci due to reverberating echoes, resulting in the "dirty" shadowing indicating gas within the scrotal wall $[5,10]$. We observed gas formation in 5 patients (Figure 5), fat stranding in 2 patients, abscesses in 2 patients, and localized fluid

Table 1. Early Signs of Fournier Gangrene Comparison with patients who had undergone CT compared with those who had not received CT examination

\begin{tabular}{|c|c|c|c|c|c|}
\hline & & $\mathrm{n} / \%$ & CT & $\mathrm{CT}$ & $P$-value* \\
\hline & & & no & yes & \\
\hline \multirow[t]{4}{*}{ sex } & female & $\mathrm{n}$ & 1 & 5 & 1.000 \\
\hline & & $\%$ & $25.00 \%$ & $17.20 \%$ & \\
\hline & male & $\mathrm{n}$ & 3 & 24 & \\
\hline & & $\%$ & $75.00 \%$ & $82.80 \%$ & \\
\hline \multirow[t]{4}{*}{ gas } & no & $\mathrm{n}$ & 0 & 6 & 1.000 \\
\hline & & $\%$ & $0.00 \%$ & $20.70 \%$ & \\
\hline & yes & $\mathrm{n}$ & 4 & 23 & \\
\hline & & $\%$ & $100.00 \%$ & $79.30 \%$ & \\
\hline \multirow[t]{4}{*}{ fat stranding } & no & $\mathrm{n}$ & 4 & 1 & $<0.001$ \\
\hline & & $\%$ & $100.00 \%$ & $3.40 \%$ & \\
\hline & yes & $\mathrm{n}$ & 0 & 28 & \\
\hline & & $\%$ & $0.00 \%$ & $96.60 \%$ & \\
\hline \multirow[t]{4}{*}{ fluid } & no & $\mathrm{n}$ & 1 & 10 & 1.000 \\
\hline & & $\%$ & $25.00 \%$ & $34.50 \%$ & \\
\hline & yes & $\mathrm{n}$ & 3 & 19 & \\
\hline & & $\%$ & $75.00 \%$ & $65.50 \%$ & \\
\hline \multirow[t]{4}{*}{ perineum } & no & $\mathrm{n}$ & 3 & 3 & $<0.014$ \\
\hline & & $\%$ & $75.00 \%$ & $10.30 \%$ & \\
\hline & yes & $\mathrm{n}$ & 1 & 26 & \\
\hline & & $\%$ & $25.00 \%$ & $89.70 \%$ & \\
\hline \multirow[t]{4}{*}{ scrotum } & no & $\mathrm{n}$ & 1 & 15 & 0.601 \\
\hline & & $\%$ & $25.00 \%$ & $51.70 \%$ & \\
\hline & yes & $\mathrm{n}$ & 3 & 14 & \\
\hline & & $\%$ & $75.00 \%$ & $48.30 \%$ & \\
\hline \multirow[t]{4}{*}{ perianus } & no & $\mathrm{n}$ & 4 & 16 & 0.136 \\
\hline & & $\%$ & $100.00 \%$ & $55.20 \%$ & \\
\hline & yes & $\mathrm{n}$ & 0 & 13 & \\
\hline & & $\%$ & $0.00 \%$ & $44.80 \%$ & \\
\hline \multirow[t]{4}{*}{ pubic } & no & $\mathrm{n}$ & 4 & 20 & 0.555 \\
\hline & & $\%$ & $100.00 \%$ & $69.00 \%$ & \\
\hline & yes & $\mathrm{n}$ & 0 & 9 & \\
\hline & & $\%$ & $0.00 \%$ & $31.00 \%$ & \\
\hline \multirow[t]{4}{*}{ buttock } & no & $\mathrm{n}$ & 3 & 14 & 0.601 \\
\hline & & $\%$ & $75.00 \%$ & $48.30 \%$ & \\
\hline & yes & $\mathrm{n}$ & 1 & 15 & \\
\hline & & $\%$ & $25.00 \%$ & $51.70 \%$ & \\
\hline \multirow[t]{4}{*}{ inguinal } & no & $\mathrm{n}$ & 4 & 20 & 0.555 \\
\hline & & $\%$ & $100.00 \%$ & $69.00 \%$ & \\
\hline & yes & $\mathrm{n}$ & 0 & 9 & \\
\hline & & $\%$ & $0.00 \%$ & $31.00 \%$ & \\
\hline
\end{tabular}


Table 2. Comparison of disease characteristics and location

\begin{tabular}{|c|c|c|c|c|c|c|c|c|c|c|c|c|c|c|}
\hline & & & gas & & & $\begin{array}{c}\text { fat } \\
\text { stranding }\end{array}$ & & & abscess & & & fluid & & \\
\hline & & & no & yes & $P$-value & no & yes & $P$-value & no & yes & $P$-value & no & yes & $P$-value \\
\hline \multirow[t]{4}{*}{ sex } & female & $\mathrm{n}$ & 1 & 5 & 1.000 & 1 & 5 & 1.000 & 3 & 3 & 1.000 & 2 & 4 & 1.000 \\
\hline & & $\%$ & $16.70 \%$ & $18.50 \%$ & & $20.00 \%$ & $17.90 \%$ & & $21.40 \%$ & $15.80 \%$ & & $18.20 \%$ & $18.20 \%$ & \\
\hline & male & $\mathrm{n}$ & 5 & 22 & & 4 & 23 & & 11 & 16 & & 9 & 18 & \\
\hline & & $\%$ & $83.30 \%$ & $81.50 \%$ & & $80.00 \%$ & $82.10 \%$ & & $78.60 \%$ & $84.20 \%$ & & $81.80 \%$ & $81.80 \%$ & \\
\hline \multirow[t]{4}{*}{ perineum } & no & $\mathrm{n}$ & 1 & 5 & 1.000 & 3 & 3 & $<0.031$ & 5 & 1 & 0.062 & 1 & 5 & 0.637 \\
\hline & & $\%$ & $16.70 \%$ & $18.50 \%$ & & $60.00 \%$ & $10.70 \%$ & & $35.70 \%$ & $5.30 \%$ & & $9.10 \%$ & $22.70 \%$ & \\
\hline & yes & $\mathrm{n}$ & 5 & 22 & & 2 & 25 & & 9 & 18 & & 10 & 17 & \\
\hline & & $\%$ & $83.30 \%$ & $81.50 \%$ & & $40.00 \%$ & $89.30 \%$ & & $64.30 \%$ & $94.70 \%$ & & $90.90 \%$ & $77.30 \%$ & \\
\hline \multirow[t]{4}{*}{ scrotum } & no & $\mathrm{n}$ & 4 & 12 & 0.398 & 1 & 15 & 0.335 & 7 & 9 & 1.000 & 6 & 10 & 0.721 \\
\hline & & $\%$ & $66.70 \%$ & $44.40 \%$ & & $20.00 \%$ & $53.60 \%$ & & $50.00 \%$ & $47.40 \%$ & & $54.50 \%$ & $45.50 \%$ & \\
\hline & yes & $\mathrm{n}$ & 2 & 15 & & 4 & 13 & & 7 & 10 & & 5 & 12 & \\
\hline & & $\%$ & $33.30 \%$ & $55.60 \%$ & & $80.00 \%$ & $46.40 \%$ & & $50.00 \%$ & $52.60 \%$ & & $45.50 \%$ & $54.50 \%$ & \\
\hline \multirow[t]{5}{*}{ perianus } & no & $\mathrm{n}$ & 3 & 17 & 0.659 & 5 & 15 & 0.131 & 7 & 13 & 0.472 & 7 & 13 & 1.000 \\
\hline & & $\%$ & $50.00 \%$ & $63.00 \%$ & & $100.00 \%$ & $53.60 \%$ & & $50.00 \%$ & $68.40 \%$ & & $63.60 \%$ & $59.10 \%$ & \\
\hline & yes & $\mathrm{n}$ & 3 & 10 & & 0 & 13 & & 7 & 6 & & 4 & 9 & \\
\hline & & $\%$ & $50.00 \%$ & $37.00 \%$ & & $0.00 \%$ & $46.40 \%$ & & $50.00 \%$ & $31.60 \%$ & & $36.40 \%$ & $40.90 \%$ & \\
\hline & & $\%$ & $16.70 \%$ & $29.60 \%$ & & $0.00 \%$ & $32.10 \%$ & & $35.70 \%$ & $21.10 \%$ & & $54.50 \%$ & $13.60 \%$ & \\
\hline \multirow[t]{4}{*}{ buttock } & no & $\mathrm{n}$ & 5 & 12 & 0.175 & 4 & 13 & 0.335 & 7 & 10 & 1.000 & 6 & 11 & 1.000 \\
\hline & & $\%$ & $83.30 \%$ & $44.40 \%$ & & $80.00 \%$ & $46.40 \%$ & & $50.00 \%$ & $52.60 \%$ & & $54.50 \%$ & $50.00 \%$ & \\
\hline & yes & $\mathrm{n}$ & 1 & 15 & & 1 & 15 & & 7 & 9 & & 5 & 11 & \\
\hline & & $\%$ & $16.70 \%$ & $55.60 \%$ & & $20.00 \%$ & $53.60 \%$ & & $50.00 \%$ & $47.40 \%$ & & $45.50 \%$ & $50.00 \%$ & \\
\hline
\end{tabular}

The $P$-values were derived using Fisher's exact test.

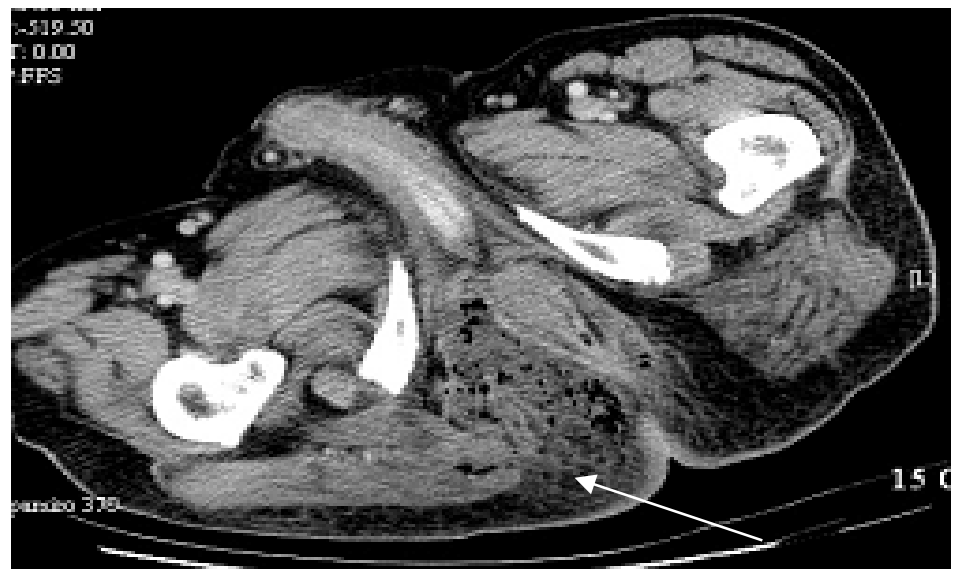

Figure 1. Fournier gangrene in a 66-year-old man. Contrast material-enhanced CT shows fatty infiltration and thickening of the right perineum fascia via the Colles' fascia and extensive inflammatory changes and gas pockets (arrows).

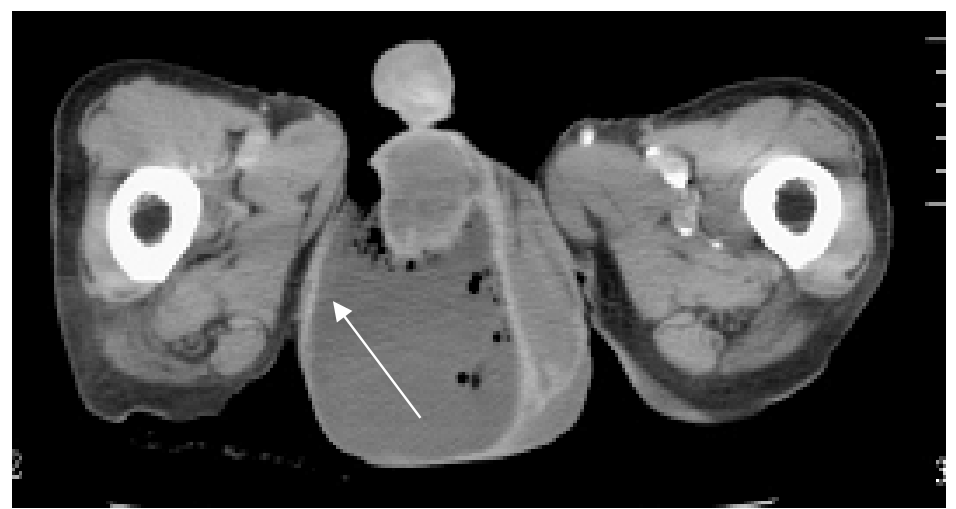

Figure 2. Fournier gangrene in a 72-year-old man with scrotal swelling, pain, and redness. Contrast-enhanced CTs show a markedly enlarged scrotal sac containing foci of gas, fluid retention, and abscess formation (arrows) (more on the right side than on the left 
accumulation in 5 patients. Disease location in the perineum is noted in 3 patients, in the scrotum in 6 patients, in the peri-anal region in 1 patient, in the buttock in 1 patient, and in the inguinal region in 1 patient.

\section{Conventional radiography}

In all the 6 patients who received conventional radiographic studies, lucencies due to gas in the soft tissues were observed (Figure 6) [5,17]. Disease location in the perineum is noted in 5 patients, in the scrotum in 2 patients, in the peri-anal region in 4 patients, in the buttocks in 4 patients, and in the inguinal region in 1 patient.

\section{Discussion}

Fournier gangrene (FG) was first described by Jean Alfred Fournier, a French venereologist, in 1883. At that time, it was described as a condition abrupt in onset and characterized by rapid progression to gangrene [5,9]. FG is predominantly observed in middle-aged men from 50 to 60 years old $[3-6,11,18]$. This condition is less frequently encountered in women and children. Men are 10 times more likely to

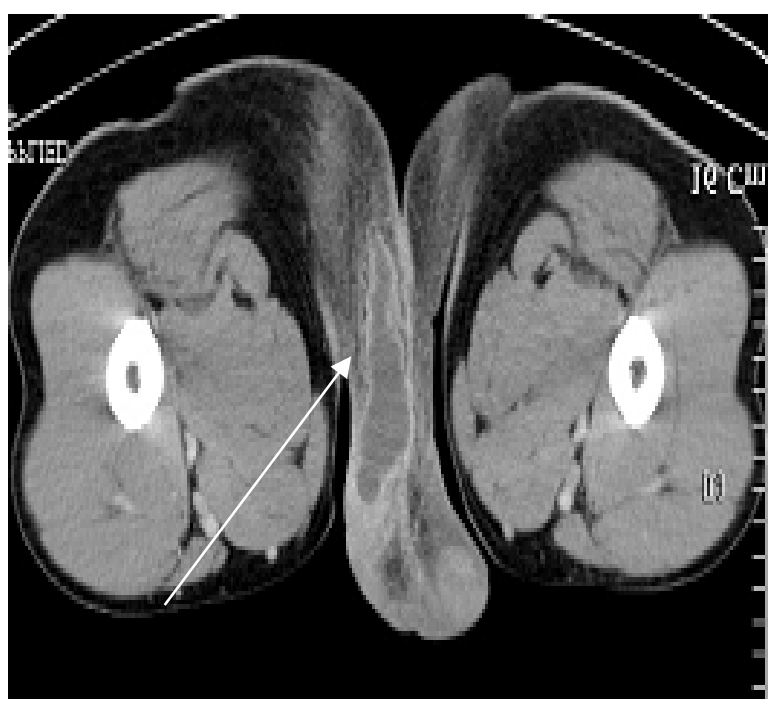

Figure 3. Fournier gangrene of the penile shaft in a 46-year-old man. Contrast-enhanced CT shows fluid and abscess (arrows) tracking in the right corpora cavernosa

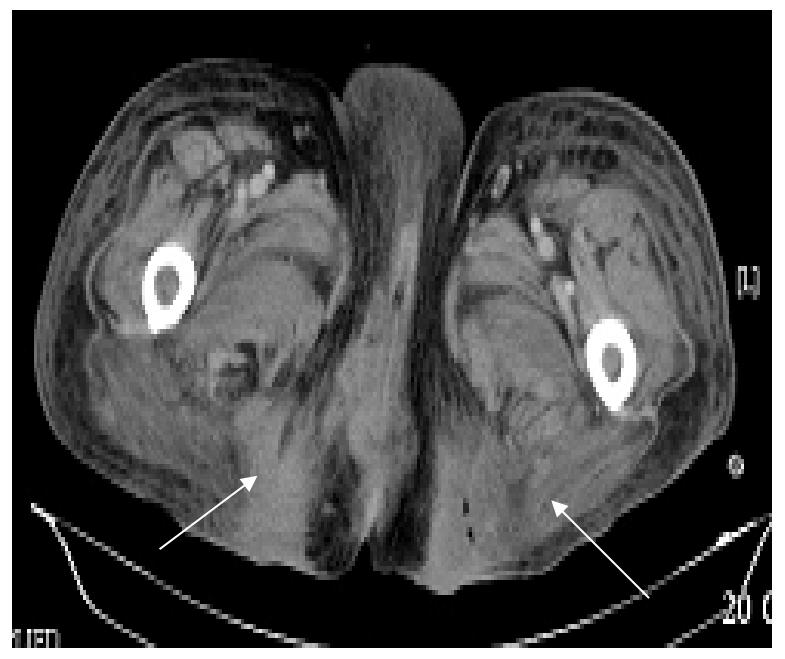

Figure 4. Fournier gangrene in a 76-year-old woman. Contrast material-enhanced CT shows thickening of the right perineum fascia via the Colles' fascia and extensive inflammatory changes, abscess formation, and mild left-side gas pockets (arrows)

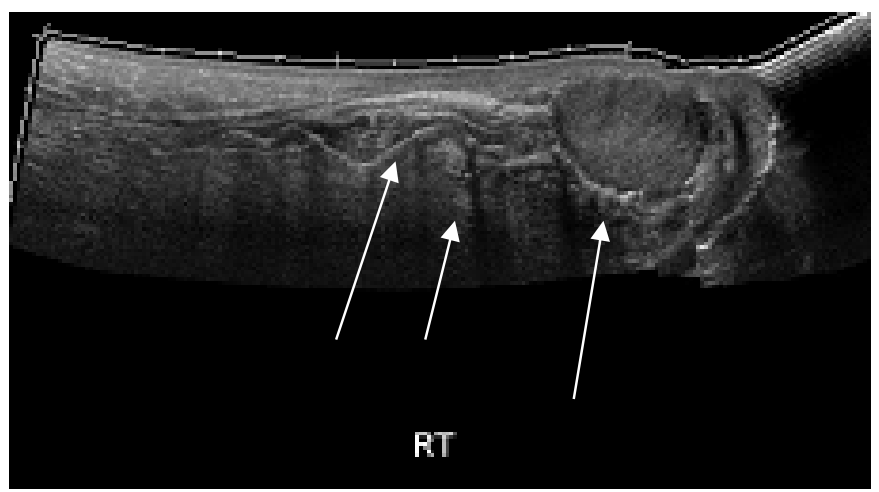

Figure 5. Fournier gangrene in a 74-year-old man with fever. Ultrasound image shows echogenic areas (curved arrows) with dirty shadowing representing gas in the right scrotal wall and perineum

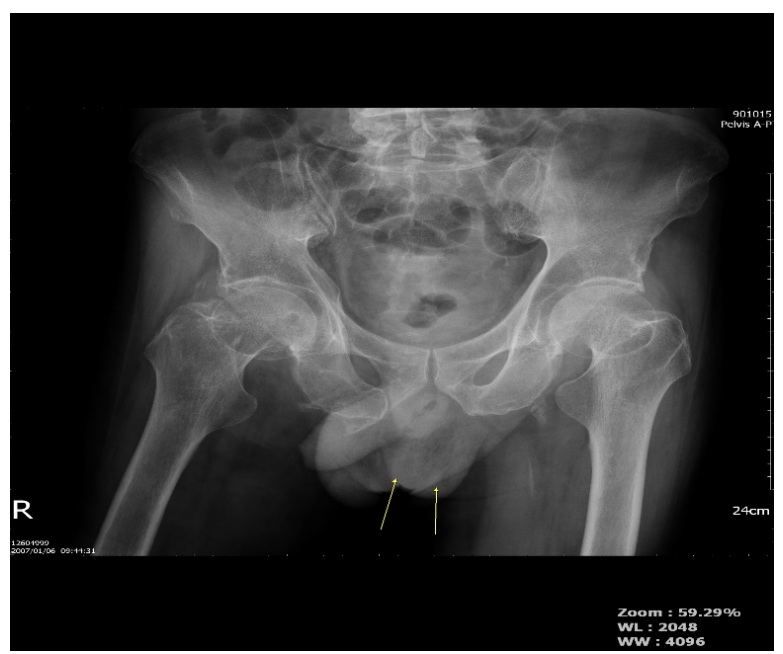

Figure 6. Fournier gangrene in a 58-year-old man with a history of testicular pain and skin infection. Anteroposterior scout radiograph shows numerous radiolucent pockets (arrows) in the soft tissues overlying the region of the left scrotum

develop FG than women $[2,5,11,13]$. This is perhaps because of the presence of a more robust lymphatic drainage of the female perineum via the vaginal route, thus discouraging the development of FG $[2,5,13]$. However, it is also suspected than the diagnoses of FG in women are under-reported [5,12]. Fournier gangrene is most often due to a localized infection adjacent to the point of entry, including abscesses (particularly in the peri-anal, peri-rectal, and ischio-rectal regions), anal fissures, and colonic perforations. Although the actual incidence of FG is difficult to establish, this disease is relatively rare. The most common predisposing factors for the development of FG are diabetes mellitus and alcohol abuse [5,6,11].

Coexisting diabetes mellitus has been found in up to $40-60 \%$ of patients with FG $[5,13,14]$. The most common presenting symptoms of FG include scrotal swelling, localized pain, hyperemia, pruritus, crepitus and fever $[5,11,12]$. The onset of symptoms tends to develop gradually over a period of 2-7 days. Air in the soft tissues represents insoluble gas produced by anaerobic bacteria and consists primarily of nitrogen, hydrogen, nitrous oxide, and hydrogen sulfide $[5,8,10]$. Systemic manifestations in patients of FG may include leukocytosis, dehydration, tachycardia, and hyperglycemia [5,8,9,15]. Elevated leukocyte counts in the blood and urine, elevated C-reactive protein levels, or hyperglycemia are helpful clues in establishing the diagnosis of FG, as this condition tends to be polymicrobial in nature with a 
synergy between aerobic and anaerobic bacteria. An average of more than three organisms is generally in each individual patient. The most commonly encountered microbes are Escherichia coli (aerobe) and followed by Enterococcus (aerobe) [5,11].

Imaging findings may also provide helpful clues in predicting the pathogens involved. Infections in FG tend to spread along fascial planes (Figures 2 and 3), but it can also spread along the Colles' fascia (superficial perineal fascia) and progress anteriorly along the Dartos to involve the scrotum and penis. The infection can also spread to the ischio-rectal fossa and subsequently to the buttocks and thighs (Figure 3).

Inflammation and edema from the infection result in impaired local circulation, leading to vascular thromboses in the cutaneous and subcutaneous tissues, followed later by skin necrosis due to interrupted blood supply. Peri-fascial dissection with subsequent spread of bacteria and progression to gangrene of the overlying tissues are ensuing events. The rate of fascial necrosis has been noted to be as high as $2-3 \mathrm{~cm}$ per hour, making early diagnosis crucial $[5,6,7]$. Histologic analyses reveal necrotic superficial fascia, leukocytic infiltration of the deep fascial layers, and fibrinoid thromboses of the arterioles and venules with vascular wall necroses. Microbial infiltration of destroyed fascia with intact superficial epidermis is also observed.

Treatments of FG include broad-spectrum antibiotics with multiple antimicrobial agents and complete surgical debridement of necrotic tissue $[19,20]$. The overall mortality rate of FG ranges from $15 \%$ to $50 \%$ [1-5].

Imaging findings of fat infiltration often suggest an early sign for the diagnosis of FG. In its early stage, it is possible for subtle inflammatory changes to be detected. However, they are easily overlooked if not intentionally sought out. In the early stages of $\mathrm{FB}$, computed tomography may demonstrate progressive fat infiltration, possibly with no evidence of subcutaneous emphysema as of yet. The perineum is the most common location for the development of FG.

The characteristic ultrasonographic finding in FG is gas within the thickened and edematous scrotal wall (Figure 5) $[5,7,8,10,15,21]$. Imaging evidence of gas within the scrotal wall may be detected before crepitus becomes clinically apparent. However, the role of this finding is limited to detecting the extent of disease and its underlying causes $[5,10,21]$.

On conventional radiographs, lucencies representing soft tissue gas may be seen in the region overlying the scrotal and/or perineum (Figure 6). Deep fascial gas is rarely seen on conventional radiographs, indicating a significant disadvantage of this modality in the diagnosis and evaluation of FG $[5,22,17]$.

Few reports describing the MRI findings of FG are available in the published literature [23]. MRI has proven to be highly useful for identifying the extent of necrosis and in determining the extent of surgical debridement necessary to ensure adequate disease eradication. However, differentiating soft tissue gas from signal void due to vascular flow or a phlebolith-like stone is may be difficult. Because soft tissue gas is an important characteristic finding in the diagnosis of FG, MRI may not be the best choice regarding imaging studies unless in settings in which patients are critically ill and frequently intubated $[21,23]$.

Findings of FG on PET-CT are mentioned in few studies in available published literature $[24,25]$. The principal role of PET-CT is in tumor staging, treatment planning, and defining tumor response to clinical intervention. If clinical symptoms and diagnoses are not clear, PET-CT may play complementary roles in the diagnosis of FG and assessment of response to treatment. However, PET-CT is expensive and may not be appropriate for some patients.

Recognizing the early signs of FG in imaging studies is crucial in establishing early diagnosis and ensuring adequate intervention. Fat infiltration is a characteristic finding in the disease's early stages, whilst abscess formation, soft tissue gas and fluid retention may be present in its more advanced conditions.

The study we have hereby conducted is not without its limits. This is a retrospective study of patients from a single institution. Furthermore, the number of patients studied is small because FG is such an uncommon diagnosis; the statistical significance of the findings cannot be predicted with such a small number. In addition, control cases are not available to make calculations of sensitivity and specificity possible.

In conclusion, $\mathrm{CT}$ is the preferred imaging modality in the diagnosis of FG because it is widely available, fast, and excellent in identifying the early signs of disease such as fat infiltration and location of disease in the perineum. CT is superior to both ultrasound and conventional radiography in demonstrating FG, assessing the extent of disease, and evaluation of its possible underlying causes.

\section{References}

1. Amendola MA, Casillas J, Joseph R, Antun R, Galindez O (1994) Fournier's gangrene: CT findings. Abdom Imaging 19: 471-474. [Crossref]

2. Eke N (2000) Fournier's gangrene: a review of 1726 cases. Br J Surg 87: 718-728 [Crossref]

3. Jeong HJ, Park SC, Seo IY, Rim JS (2005) Prognostic factors in Fournier gangrene. Int J Urol 12: 1041-1044. [Crossref]

4. Tahmaz L, Erdemir F, Kibar Y, Cosar A, Yalcýn O (2006) Fournier's gangrene: report of thirty-three cases and a review of the literature. Int J Urol 13: 960-967. [Crossref ]

5. Levenson RB, Singh AK, Novelline RA (2008) Fournier gangrene: role of imaging. Radiographics 28: 519-528. [Crossref]

6. Safioleas M, Stamatakos M, Mouzopoulos G, Diab A, Kontzoglou K, et al. (2006) Fournier's gangrene: exists and it is still lethal. Int Urol Nephrol 38: 653-657. [Crossref]

7. Uppot RN, Levy HM, Patel PH (2003) Case 54: Fournier gangrene. Radiology 226 115-117. [Crossref]

8. Rajan DK, Scharer KA (1998) Radiology of Fournier's gangrene. AJR Am J Roentgenol 170: 163-168. [Crossref]

9. Ochiai T, Ohta K, Takahashi M, Yamazaki S, Iwai T (2001) Fournier's gangrene: report of six cases. Surg Today 31: 553-556. [Crossref]

10. 10.Kane CJ, Nash P, McAninch JW (1996) Ultrasonographic appearance of necrotizing gangrene: aid in early diagnosis. Urology 48:142-144. [Crossref ]

11. Atakan IH, Kaplan M, Kaya E, Aktoz T, Inci O (2002) A life-threatening infection: Fournier's gangrene. Int Urol Nephrol 34: 387-392. [Crossref ]

12. Gürdal M, Yücebas E, Tekin A, Beysel M, Aslan R, et al. (2003) Predisposing factors and treatment outcome in Fournier's gangrene. Analysis of 28 cases. Urol Int 70: 286290. [Crossref ]

13. Grayson DE, Abbott RM, Levy AD, Sherman PM (2002) Emphysematous infections of the abdomen and pelvis: a pictorial review. Radiographics 22: 543-561. [Crossref]

14. Yanar H, Taviloglu K, Ertekin C, Guloglu R, Zorba U, et al. (2006) Fournier's gangrene: risk factors and strategies for management. World J Surg 30: 1750-1754. [Crossref ]

15. Piedra T, Ruíz E, González FJ, Arnaiz J, Lastra P, et al. (2006) Fournier's gangrene: a radiologic emergency. Abdom Imaging 31: 500-502. [Crossref ]

16. Sherman J, Solliday M, Paraiso E, Becker J, Mydlo JH (1998) Early CT findings of Fournier's gangrene in a healthy male. Clin Imaging 22: 425-427. [Crossref]

17. Chen CC, Su YJ (2011) X-ray diagnosis of fatal Fournier's gangrene caused by Klebsiella pneumoniae. Emerg Med J 28: 174. [Crossref ]

18. Rotondo N (2002) Fournier's gangrene: an unusual presentation of sepsis. $J$ Emerg Med 23: 413-414. [Crossref ] 
19. Thwaini A, Khan A, Malik A, Cherian J, Barua J, et al. (2006) Fournier's gangrene and its emergency management. Postgrad Med J 82: 516-519. [Crossref]

20. Cameron JL (2004) Current surgical therapy. 8th Edn. Elsevier Mosby, Philadelphia.

21. Wysoki MG, Santora TA, Shah RM, Friedman AC (1997) Necrotizing fasciitis: CT characteristics. Radiology 203: 859-863. [Crossref]

22. Tomono H, Kitamura H, Iwase M, Kuze S, Toyoda H, et al. (2004) Successful treatment of Fournier's gangrene with the assistance of preoperative computed tomography in an elderly man: report of a case. Surg Today 34: 383-385. [Crossref ]
23. Fillo J, Cervenakov I, Labas P, Mardiak J, Szoldová K, et al. (2001) Fournier's gangrene: can aggressive treatment save life? Int Urol Nephrol 33: 533-536. [Crossref ]

24. Yoneda A, Fujita F, Tokai H, Ito Y, Haraguchi M, et al. (2010) MRI can determine the adequate area for debridement in the case of Fournier's gangrene. Int Surg 95: 76-79. [Crossref]

25. Sürücü E, Canda AE, Kaya GC, Tuna B, Sengoz T, et al. (2010) F-18 fluorodeoxyglucose PET in Fournier gangrene. Clin Nucl Med 35: 625-627. [Crossref ]

Copyright: $(02018$ Lin MP. This is an open-access article distributed under the terms of the Creative Commons Attribution License, which permits unrestricted use, distribution, and reproduction in any medium, provided the original author and source are credited. 